carbonate, prior to the addition of hydrogen peroxide. A study of transmission curves showed that addition of bicarbonate caused a considerable decrease in the absorption of solutions in the near ultra-violet (350-400 $\mathrm{m} \mu)$; but the effect became less marked at longer wave-lengths and disappeared entirely in the region 440-450 $\mathrm{m} \mu$. The reason for consistency of results with the Pulfrich photometer thus becomes apparent, and no error will occur using a spectrophotometer if readings are made at $440-450 \mathrm{~m} \mu$; but certain precautions must be taken if it is desired to take advantage of the greater sensitivity obtained when measurements are made at lower wave-lengths.

Since the magnitude of the error varies with the amount of bicarbonate as well as with the concentration of sodium carbonate, a correction is difficult to apply, and it is necessary instead to ensure that no appreciable quantities of bicarbonate are present. This cannot be conveniently done by boiling the solutions, since the presence of excess sodium carbonate causes a marked decrease in the rate of decom. position of bicarbonate, and appreciable quantities of the latter may persist in solution after boiling for more than an hour. The most reliable technique is to avoid the formation of bicarbonate altogether by neutralizing the acid solutions containing uranium with sodium hydroxide; the neutral solutions are then treated with sodium carbonate and the colour developed as usual with hydrogen peroxide.

Further details of experiments and discussion of results will be published elsewhere.

Division of Industrial Chemistry, Council for Scientific and Industrial Research, Melbourne. Aug. 3.

1 Sandell, E. B., "Colorimetric Determination of Traces of Metals" (Interscience Publishers, Inc., New York, 1944).

\section{Insecticidal Power and Microscopical Struc- ture of Residual Films of Phenyl-isonitrile and Benzene Hexachloride}

IN the fight against pistachio nutworm (Eurytoma pistacice, Anagnos) and pistachio tree leafhopper (Idiocerus pistacioe), we made use of a new insecticide, the basis of which is phenyl-isonitrile. At first it was mixed with nicotine and lead arsenate ; later, instead of nicotine and lead arsenate, we added benzene hexachloride. This preparation proved to be promising, owing to the fact that the one constituentphenyl-isonitrile-kills the insects and at the same time repels them, while the other constituentbenzene hexachloride-not only kills them but also causes the preparation to remain active for a much longer period. This preparation is used in the form of a water-suspension which is sprinkled on the trees diluted with water.

A. J. Musgrave ${ }^{1}$ found that residual films of a sample of technical grade benzene hexachloride prepared on glass plates from chloroform solutions showed a stronger insecticidal power than other samples of different manufacture. A microscopical examination carried out by him showed that the film was present in the form of discrete globules. $\mathrm{He}$ suggests that high toxicity may be associated with traces of chloroform retained by the film.

We prepared several residual films, on glass plates, of benzene hexachloride as well as of mixtures of benzene hexachloride and phenyl-isonitrile, and we tested them on a species of Myrmicine ant which shows almost the same resistance to insecticides as does Eurytoma pistacice.

We find that the toxicity does not depend on the organic solvent-chloroform, benzene, alcohol, kerosene oil-from which the film is prepared, but it is in direct proportion to the capacity of the insecticide to adhere on the insect. Comparative tests carried out on glass plates dusted with these insecticides in the form of dry dust containing inert matter showed that the death of the insect occurs more quickly -in about half the time-than when the films were prepared from solutions of the insecticides in organic solvents, in which case the film is better retained on the plate. The quantity of the insecticide used in both cases was the same.

Furthermore, films prepared from solutions of the insecticides killed the insects more quickly when some traces of the organic solvent could be retained in any way by the film. It is justifiable to say that this is due to the greater adhesion of this form of film to the insects. Pure vapours of organic solvents do not seem to cause death of the insects but only a transitory unconsciousness.

A similar effect happens in the case observed by Musgrave. The insect Dermestes maculatus Deg., walking on the film, which was present in the form of discrete globules containing traces of chloroform, caused crystallization of the benzene hexachloride, but at the same time owing to the presence of traces of the solvent the insecticide adhered better to the insect. Another fact which must be taken into con. sideration is that the vapour pressure of the insecticide in the form of discrete globules is greater than that in any other form, as then the insecticide is in the condition of a supersaturated solution; it is known that benzene hexachloride acts as a fumigant as well as a stomach and contact poison.

In general, benzene hexachloride as well as mixtures of benzene hexachloride and phenyl-isonitrile form residual films of greater toxicity when the films are prepared from solutions with organic solvents, instead of water-suspensions of a wettable form of the insecticides (the insecticide contains inert matter with a wetting agent). Unfortunately, most organic solvents 'burn' the plants. The mixture of benzene hexachloride and phenyl-isonitrile had a higher toxicity than either benzene hexachloride or phenylisonitrile alone.

The experiments are being continued.

MICHAEL DEFFNER

DEM. Augustides

"Nicolaos Canellopoulos"

Institute of Chemistry and Agriculture, Piræus. Nov. 3.

${ }^{1}$ Musgrave, A. J., Nature, 162, 296 (1948).

\section{A Saprophytic Liverwort}

THE saprophytic liverwort described in this communication was found by Mr. M. V. Brian, of the Department of Zoology in this University, early in December 1948, while investigating an ant's nest in a wood near Cardross, Dumbartonshire. The first specimens found and brought into the Botany Department were white, fleshy, irregularly lobed bodies which were provisionally identified as the thalli of a liverwort. A little later, Mr. Brian found further material, which, since it bore young sporogonia, could be identified as a species of Aneura, or, at any rate, as being closely related to that genus. 